\title{
Does Reinsurance Need Reinsurers?
}

\author{
Guillaume Plantin ${ }^{12}$
}

February 2005

\footnotetext{
${ }^{1}$ Tepper School of Business, Carnegie Mellon University, 5000 Forbes Avenue, Pittsburgh, PA 15213. Phone: 412-268-9823. E-mail: gplantin@andrew.cmu.edu

${ }^{2}$ I thank participants at the 27th EGRIE seminar, at seminars at the University of Chicago and the MIT Sloan School of Management, and in particular, JeanLuc Besson, Bruno Biais, Pierre-Andre Chiappori, Georges Dionne, Rick Green, Pierre-Francois Koehl, Pierre Picard, Jean-Charles Rochet, Jean Tirole, and an anonymous referee for very helpful comments. Errors are mine.
} 


\begin{abstract}
The reinsurance market is the secondary market for insurance risks. It has a very specific organization. Direct insurers rarely trade risks with each other. Rather, they cede part of their primary risks to specialized professional reinsurers who have no primary business. This paper offers a model of equilibrium in reinsurance and capital markets in which professional reinsurers arise endogenously. Their role is to monitor primary insurers credibly, so that insurers can raise capital more easily. In equilibrium, the financial structure of primary insurers consists of a mix of reinsurance and outside capital. The comparative statics yield empirical predictions which are broadly in line with a number of stylized facts from the reinsurance market.
\end{abstract}




\section{Introduction}

The reinsurance market is the secondary market for insurance risks. Reinsurance is an important feature of the non-life insurance industry. According to the latest global study on external reinsurance released by Swiss Re (1998), direct non-life insurers have ceded business worth USD 103 billion in 1997. This corresponds to an average cession rate, or ceded premiums in terms of direct insurance premiums, of $14 \% .^{1}$

The reinsurance market has a very specific, "pyramidal" organization. The generic reinsurance deal involves two types of pure players, a primary, or direct, insurer and professional reinsurers. The primary insurer cedes part of the risks she underwrites on the primary market to the professional reinsurers. Professional reinsurers accept such secondary risks, but do not carry out any primary business. This is not to deny that some risk transfer between direct insurers who are not part of the same group also takes place. But the bulk of external reinsurance transactions comply with this pattern. According to estimates from Swiss Re (1998), the reinsurance business is dominated by specialized reinsurance companies. Professional reinsurers provide more than $80 \%$ of the global reinsurance capacity, with the top four providing around $30 \%$ of this capacity.

Economists have provided two theoretical frameworks to analyze reinsur-

\footnotetext{
${ }^{1}$ In this paper, we focus on external reinsurance, as opposed to internal reinsurance, where the former consists of reinsurance transactions completed via the marketplace, while the latter points at reinsurance arrangements within insurance groups. It is difficult in general to disentangle external from internal reinsurance in the data, because insurance accounting norms do not require separate accounting in many countries. The study of Swiss Re (1998) does deal with market transactions only.
} 
ance. The first one, pioneered by Borch (1962), consists in viewing reinsurance through the lens of optimal risk sharing among risk-averse agents. Several pieces of evidence suggest, however, that optimal risk sharing is not the only motive for reinsurance in practice. For instance, studying the reinsurance demand of a sample of U.S. insurance companies which are not part of a group, Mayers and Smith (1990) find that less diversified firms, either geographically or across business lines, purchase less reinsurance, which seems inconsistent with the view of reinsurance as a diversification device. More generally, optimal risk sharing predicts that insurance companies should end up with a net portfolio equal to a deterministic function of the gross insurance market portfolio. Professional reinsurers do indeed hold very diversified portfolios, both geographically and across insurance lines, and thus their behavior seems in line with the mutualization principle. In contrast, however, primary insurers use reinsurance mainly to cede risks, so that their net portfolios are roughly a deterministic function of their own gross portfolios only, apart from the introduction of reinsurers' default risk. ${ }^{2}$

The second framework to analyze reinsurance borrows from corporate hedging theory. The starting point is to note, as in Mayers and Smith (1990), that the decision of an insurer to purchase reinsurance resembles the decision of any non-financial firm to purchase insurance. Thus, the motivations that explain why firms hedge and why insurers demand reinsurance may well be similar. This approach has emphasized that reinsurers, because of their expertise in risk management, provide real services to primary insurers and are able to mitigate agency problems within insurance companies. The ev-

\footnotetext{
${ }^{2}$ This risk has been historically small: There is no example, to our knowledge, of contagion via reinsurance in the modern financial era.
} 
idence from Mayers and Smith (1990) that less diversified insurers demand less reinsurance is consistent with this view: highly focused insurers are more likely to develop the required expertise in-house.

Both approaches leave important points unexplained. They do not offer clear-cut rationales for the pyramidal organization of the market. They also miss the dual nature of reinsurance. As emphasized by Garven and LammTennant (2003), reinsurance is both a risk management and a financing decision. A sufficiently high credit standing is a necessary input for insurance business (see, e.g., Doherty and Tinic, 1981), and capital and reinsurance are two (imperfect) substitutes which can be used to meet this requirement. This is documented by Garven and Lamm Tennant (2003), who find that reinsurance demand increases with financial leverage. That in most prudential regulations (e.g., the U.S. Risk Based Capital or the European Solvency Margin), the minimum capital requirement is explicitly reduced by reinsurance purchase is also consistent with this dual nature of reinsurance.

Thus, it seems appropriate to model reinsurance as only one of the levers available to insurance companies in search of an optimal financial structure, and to take into account the interplay of reinsurance and other financing decisions. This paper offers a parsimonious theory of reinsurance which predicts the emergence of specialized reinsurers, and which addresses the coordination of reinsurance and financing policies. In the model, primary insurance companies make simultaneous reinsurance and financial decisions. In equilibrium, they optimally mix cessions to professional reinsurers and issuance of outside equity. The key ingredient of our model is a difference in the relative expertise of risk managers and outside financiers. This creates a 
moral-hazard problem which may prevent insurance companies from meeting capital requirements with uninformed outside finance. A natural way to overcome this agency problem is to have insurance companies financed partially with informed capital. This can be achieved by having insurers supply reinsurance capacity to each other. If reinsurers have a sufficient stake in a primary portfolio, they are credible monitors in the eyes of outside financiers, who then are willing to supply capital. However, if the important resource of this economy, informed capital, is too scarce, this comes at the cost of some insurers giving up their primary business to devote their resources entirely to reinsurance: insurers become professional reinsurers.

Moral hazard is a plausible friction in non-life insurance because of the inversion of the production cycle and the importance of loss mitigation. The production costs of an insurance company (claims) are revealed only a long time after business has been underwritten and premiums paid in. Moreover, the eventual losses depend heavily upon an insurer's ability and efforts to mitigate losses during the run-off period. These efforts are unlikely to be verifiable by non-expert outsiders, such as shareholders without a seat on the board. Indeed, it is not difficult for a claims manager to underreserve, namely, underestimate the final value of claims, for several years. Illiquidity does not precede insolvency as in industries with a normal cycle. The following statement from Warren Buffet in the Berkshire Hathaway 2002 Shareholders Letter epitomizes that this moral hazard problem is an important concern in non-life insurance:

"I can promise you that our top priority going forward is to avoid inadequate reserving. But I can't guarantee success. The 
natural tendency of most casualty-insurance managers is to underreserve, and they must have a particular mindset - which, it may surprise you, has nothing to do with actuarial expertise - if they are to overcome this devastating bias."

As is well acknowledged by practitioners, reinsurers have the ability to mitigate this problem because: (i) they have more information about claims and more risk-management skills than outside financiers; and, (ii) they are in general involved in a long-run, repeated relationship with ceding companies who then behave so as to build a reputation. Doherty and Smetters (2002) find evidence that reinsurers play a role in loss mitigation, either by monitoring ceding companies or by designing efficient dynamic contracts (experience rating).

The paper is organized as follows. Section 1 outlines the model and solves for the equilibrium. Section 2 draws empirical implications from the comparative statics. Section 3 concludes.

\section{Model}

The setup is an extension of the model of financial intermediation developed by Holmstrom and Tirole (1997). Roughly, while Holmstrom and Tirole consider an economy in which entrepreneurs cannot monitor each other, ${ }^{3}$ this assumption is relaxed here: insurers can monitor each other. First, we introduce the main building block of the model, capital constraints in the

\footnotetext{
3 "We assume that firms cannot monitor other firms, perhaps because they have insufficient capital to be credible monitors [...] or because they do not have the informational expertise."
} 
primary insurance business. Then, we present the general model, allowing insurers to reinsure each other, and solve for the equilibria in the reinsurance and capital markets.

\subsection{Capital Constrained Insurers}

We consider an economy with a continuum of insurers with unit mass. Each insurer $i \in[0,1]$ contemplates underwriting a primary insurance portfolio $P_{i}$.

Throughout the paper, what is referred to as an "insurer" is a close-knit team made of the top management and inside shareholders (e.g., members of the board) of an insurance company. This group has control over the risk management and loss mitigation strategy. Insurance companies, like most financial institutions, are more likely to have such skilled top managers and inside shareholders than industrial firms. In fact, this is required to obtain a license in most countries.

The model is symmetric for notational simplicity. Each portolio $P_{i}$ has the following characteristics. The gross outcome from underwriting it (initial capital plus premiums plus financial profits minus claims and administrative costs) is either nonnegative, with value $R$, or a large loss. The positive outcome occurs with probability $p$ if the insurer enters into active loss mitigation, or $p-\Delta p$ if she "shirks." However, loss mitigation is not observable and comes at the loss of a private benefit $B$. Thus, as is commonplace in models of moral hazard, effort comes at a cost but enhances the outcome in the sense of first-order stochastic dominance.

This very simple stochastic structure enables us to abstract from any security design considerations and to focus on organizational issues. The 
results are robust to more realistic claims models provided this first-order stochastic dominance property holds.

As in Holmstrom and Tirole (1997), we also make the extreme assumption that portfolios are perfectly positively correlated. This is intended to emphasize that reinsurance does not hinge on a diversification motive in this model.

We assume that each insurer needs to commit an amount of capital $I$ in order to be allowed to underwrite her portfolio. The situation we have in mind is that potential policyholders are dispersed and/or not financially sophisticated, but that they are represented imperfectly by an institution that acts as their agent, a broker or a regulator. This is in line with the representation hypothesis for prudential regulation outlined by Dewatripont and Tirole (1994). By setting a capital requirement, this institution ensures that the expected default of each insurer is below some threshold. Such a view of capital as a simple buffer underlies the actuarial approaches of insurance regulation, based on ruin theory, as well as the Value-at-Risk approaches in banking.

The representative of policyholders may be either a broker who does not offer any business to insurers whose credit rating is too low, or a prudential authority who does not let insurers operate if they fail to meet a statutory capital requirement.

Each insurer has an initial net wealth $K<I$. She can tap competitive outside investors who have unlimited financing capacities. In this case, for simplicity, she makes the investors take-it-or-leave-it offers.

All agents are risk neutral and protected by limited liability. An outside 
investment opportunity is available to all the agents, which yields an expected return of $\gamma>0$.

Following Holmstrom and Tirole (1997), we assume that

$$
p R>(1+\gamma) I>(p-\Delta p) R+B
$$

Thus, insurance is valuable only if insurers mitigate losses actively.

The model is identical to Holmstrom and Tirole (1997) so far. If an insurer finds the funding and underwrites her portolio, she has incentives to carry out efficient loss mitigation only if her stake in the positive outcome, $R_{I}$, is sufficient. More precisely, the incentive compatibility constraint is

$$
R_{I} \geq \frac{B}{\Delta p}
$$

However, outside financiers must be willing to participate, i.e.,

$$
p\left(R-R_{I}\right) \geq(1+\gamma)(I-K)
$$

As a result, insurance is feasible iff

$$
K \geq K_{1} \equiv I-\frac{p}{1+\gamma}\left(R-\frac{B}{\Delta p}\right) .
$$

"One lends only to the rich." Because active loss mitigation is not verifiable, insurers need to commit a sufficient amount of inside capital so as to credibly underwrite insurance business. Otherwise, the incentive compatible contracts do not leave an adequate surplus to outside financiers. In other words, the capital requirement $I$ induces an inside capital requirement $K_{1}$ which increases with $I$, as well as with the extent of the moral hazard problem $\frac{B}{\Delta p}$ and the cost of outside capital $\gamma$.

Note that with a more general distribution of claims, the optimal form of outside finance under our first-order stochastic dominance assumption would 
be subordinated debt (see Innes, 1990). However, insurers would still have to commit a sufficient initial amount of capital in order for deals to take place.

\subsection{Reinsurance}

For the balance of the paper, we restrict the analysis to the interesting case in which $B$ is large, so that

$$
0<K<K_{1} \equiv I-\frac{p}{1+\gamma}\left(R-\frac{B}{\Delta p}\right)
$$

Insurance remains possible under such circumstances. Indeed, departing from Holmstrom and Tirole (1997), we assume that insurers can monitor the loss mitigation carried out by their fellow insurers, because they are endowed with the required skills in risk management. Insurers are not as good, however, at monitoring the loss mitigation by the other insurers as they are in managing their own risks. One natural reason why primary insurers are only imperfectly monitored by other insurers is that part of the information relevant to manage claims is by nature "soft." The primary insurer has access to this soft information because, for instance, she owns the retail network, while the other insurers only have access to the "hard" information, essentially, that part of the information that is in the books and files of the primary insurer, but miss the soft part. An example of soft information is the primary insurer's guess about the psychology of the claimholders and thus whether they are willing to reach a quick compromise or bargain aggressively. Such a guess is built during an ongoing close interaction with the claimholders, but is difficult to quantify or describe precisely in an administrative file. ${ }^{4}$

\footnotetext{
${ }^{4}$ see Berger, Miller, Petersen, Rajan, and Stein (2001) for a related discussion of the soft and hard information relevant for loans decisions in retail banking.
} 
Formally, if the management of claims deriving from a primary portfolio $i \in[0,1]$ is monitored by other insurers, then:

1. The best they can achieve by monitoring is reducing the primary insurer $i$ 's private benefit from $B$ to $b_{I}<B$.

2. Monitoring entails a private $\operatorname{cost}, c_{R}$, shared fairly among the monitoring insurers.

Reinsurance reduces only partially the moral-hazard problem in loss mitigation $\left(B\right.$ reduces to $\left.b_{I}\right)$, and there is of course no reason outside investors, who cannot verify primary insurers' efforts, would have any ability to verify the monitoring effort.

We assume that

$$
p R-c_{R}>(1+\gamma) I \text {. }
$$

In words, despite the monitoring cost, insurance with active loss mitigation remains more valuable than the alternative investment opportunity. Also, we restrict the parameters to

$$
K<\frac{p\left(R-\frac{c_{R}}{\Delta p}\right)}{p R-c_{R}} I .
$$

This restriction is not necessary, but will enable us to focus on the most interesting case in which primary insurers tap both reinsurance and outside capital in equilibrium.

Because the monitoring of loss mitigation by other insurers comes at a private cost, there is an additional moral-hazard problem. In order to be credible monitors in the eyes of the outside financiers, the insurers who monitor a given insurer must have an incentive compatible stake in the outcome. 
Thus, they need to commit some of their capital to this monitoring activity to finance their share in the surplus. Otherwise stated, they provide reinsurance capacity to the insurer that they monitor in order to alleviate its financing constraints.

Since insurance creates excess value, it is optimal, if feasible, to have each insurer allocate part of her capital to her primary operations and part to supply reinsurance capacity to others, so that all the portfolios are underwritten. However, the following Proposition shows that this first-best situation cannot be attained if financing constraints are too important:

\section{Proposition 1}

If $0<K<K_{2} \equiv I-\frac{p}{1+\gamma}\left(R-\frac{b_{I}+c_{R}}{\Delta p}\right)$, then, even with reinsurance arrangements, all the primary risks cannot be underwritten. Thus, some insurers have to give up their primary business and become professional reinsurers.

Proof. See the Appendix.

The intuition is straightforward. When a portfolio is reinsured, the present value of the income which is pledgeable to outside investors is $\frac{p}{1+\gamma}\left(R-\frac{b_{I}+c_{R}}{\Delta p}\right)$, because $\frac{b_{I}}{\Delta p}$ and $\frac{c_{R}}{\Delta p}$ are the minimal incentive compatible stakes of the primary insurer and of her reinsurers, respectively. If this present value is smaller than the need for outside capital, because inside capital and reinsurance capacity are too small, then the capital requirements cannot be met for all the portfolios. For the remainder of the paper, we study the case in which all the primary portfolios cannot be underwritten: we assume from now on that $K<K_{2}$. 


\subsection{Reinsurers}

From Proposition 1, if $K<K_{2}$, all the primary portfolios cannot be underwritten. Thus, under such circumstances, it is must be the case that specialized reinsurers, who do not have primary business and who devote their whole capital to the supply of reinsurance capacity, emerge. We now study the equilibria in this case. Let $\lambda$ denote the proportion of insurers that act as pure reinsurers in equilibrium. Thus, the remaining $1-\lambda$ insurers underwrite the primary portfolio available to them. Let

$$
\alpha=\frac{\lambda}{1-\lambda}
$$

be the ratio of reinsurers for one primary insurer. This ratio, which will turn out to fully characterize the equilibrium, may be interpreted as the "cession rate" in the reinsurance market.

Note that while $K<K_{2}$ ensures that there must be specialized reinsurers, it does not rule out the possibility that primary insurers also supply some reinsurance capacity with a fraction of their capital. We restrict the analysis to the equilibria in which the primary insurers do not supply reinsurance capacity at all, and rather invest their whole capital in their primary business. We make this restriction because these equilibria are the most tractable, and also for a more important reason that we outline below, after the derivation of the equilibria.

There are now two moral hazard problems for a given primary portfolio. The primary insurer and her reinsurers must both behave. Thus, both the primary insurer and her reinsurers must have a sufficient stake in the positive outcome. Let $R_{I}$ and $R_{R}$ denote their respective stakes. The residual surplus can be distributed to outside investors. This determines the quantity of out- 
side finance that can be raised. Any shortfall has to be filled by the primary insurer's capital and $K_{R}$, the reinsurance capacity, namely, the capital committed by reinsurers. In equilibrium, primary insurers choose the reinsurance cover which maximizes their expected profit, and reinsurance and primary insurance yield the same expected return on informed capital $K$. Then, each agent has no incentive to change her specialization. Thus, insurers maximize $R_{I}$ subject to:

$$
\begin{aligned}
R_{I} & \geq \frac{b_{I}}{\Delta p} \\
R_{R} & \geq \frac{c_{R}}{\Delta p} \\
p\left(R-R_{I}-R_{R}\right) & \geq(1+\gamma)\left(I-K-K_{R}\right) \\
p R_{I} & =\frac{1}{\alpha}\left(p R_{R}-c_{R}\right) \geq(1+\gamma) K \\
K_{R} & =\alpha K .
\end{aligned}
$$

(II) states that the contract has to be incentive compatible for the primary insurer of a given portfolio. Her stake must be sufficiently high that she is better off managing claims efficiently given she is monitored by reinsurers.

$(R I)$ states that the contract has to be incentive compatible for the reinsurers of any given portfolio. Their stake must be sufficiently high so that they effectively monitor her.

$(O P)$ is the outside investors' participation constraint.

$(I P)$ is the participation constraints of primary insurers and reinsurers. The unitary returns from investing in a primary portfolio or supplying reinsurance capacity must be equal, so that they are indifferent in equilibrium, and it must be higher than the return of the outside opportunity. 
$(E R)$ states that the market for reinsurance capacity clears.

Note first that $(R I)$ must be binding in equilibrium: $R_{R}=\frac{c_{R}}{\Delta p}$. Reinsurance is more costly than capital because of the monitoring $\operatorname{cost} c_{R}$, so that insurers optimally minimize their cessions. Thus, substituting into $(I P)$, one finds that

$$
R_{I}=\frac{1}{\alpha}\left(\frac{p-\Delta p}{p \Delta p}\right) c_{R}
$$

Note also that $(O P)$ must be binding if outside capital is necessary, i.e., if $K+K_{R}<I$. In this case, substituting $R_{I}, R_{R}$, and $K_{R}$ into $(O P)$, we get that the equilibrium cession rate $\alpha$ is the positive root of

$$
\alpha^{2}+\rho_{I} \alpha-\rho_{R}=0
$$

where

$$
\left\{\begin{array}{c}
\rho_{I}=1+\frac{p\left(R-\frac{c_{R}}{\Delta p}\right)-(1+\gamma) I}{(1+\gamma) K} \\
\rho_{R}=\frac{p-\Delta p}{(1+\gamma) K} \times \frac{c_{R}}{\Delta p}
\end{array} .\right.
$$

Note that $\rho_{I}$ and $\rho_{R}$ relate to the respective returns earned by primary insurers and reinsurers on a given portfolio, hence the notation. It remains to verify that for such an $\alpha$ :

1. (II) is satisfied: $R_{I}$ is incentive compatible for the primary insurer.

2. The inequality in $(I P)$ is satisfied: Insurers and reinsurers do not prefer the outside opportunity.

3. Outside capital is required: $K+K_{R}<I$.

Straightforward algebra shows that the inequality in $(I P)$ is satisfied since $p R-c_{R}>(1+\gamma) I$, and that outside capital is required because we assumed $K<\frac{p\left(R-\frac{c_{R}}{\Delta p}\right)}{p R-c_{R}} I$. 
It is also easy to check that $(I I)$ amounts to $K \geq K_{3} \equiv \frac{I-\frac{p}{1+\gamma}\left(R-\frac{b_{I}+c_{R}}{\Delta p}\right)}{1+\left(1-\frac{\Delta p}{p}\right) \frac{c_{R}}{b_{I}}}$. The following Proposition summarizes the result:

\section{Proposition 2}

$$
\begin{aligned}
& \text { Let }\left\{\begin{array}{c}
\rho_{I}=1+\frac{p\left(R-\frac{c_{R}}{\Delta p}\right)-(1+\gamma) I}{(1+\gamma) K} \\
\rho_{R}=\frac{p-\Delta p}{(1+\gamma) K} \times \frac{c_{R}}{\Delta p}
\end{array} .\right. \\
& \text { If } K \geq K_{3} \equiv \frac{I-\frac{p}{1+\gamma}\left(R-\frac{b_{I}+c_{R}}{\Delta p}\right)}{1+\left(1-\frac{\Delta p}{p}\right) \frac{c_{R}}{b_{I}}} \text {, there is an equilibrium with specialized rein- }
\end{aligned}
$$
surers in which primary insurers use both reinsurance capacity and outside finance. The equilibrium cession rate $\alpha$ is the positive root of

$$
\Pi(X)=X^{2}+\rho_{I} X-\rho_{R}
$$

Namely,

$$
\alpha=\frac{1}{2}\left(\sqrt{\rho_{I}^{2}+4 \rho_{R}}-\rho_{I}\right) .
$$

Proof. See above.

Thus, assuming ex ante identical insurers with similar skills and opportunity sets, we have exhibited an equilibrium in which specialized reinsurers emerge and primary insurers mix reinsurance and outside capital. Note that if monitoring by reinsurers is very efficient, namely if $b_{I} \rightarrow 0$, then $K_{3} \rightarrow 0$. In words, it is always possible to fund some insurance capacity in this economy, even when there is only a very small amount of informed capital available.

As already mentioned, interestingly, there are also equilibria in which primary insurers provide some reinsurance capacity. Of course, specialized reinsurers still arise in these equilibria, as a consequence of $K<K_{2}$. Note that the existence of such equilibria only means that we do not predict specialized reinsurers AND specialized primary insurers. This is not actually a 
weakness of the model, but rather a strength: we mention in the introduction that while specialized reinsurers are dominant suppliers in the external reinsurance market, primary insurers also provide some capacity. The equilibrium we have focused on is actually dominant in the sense that it is the only one which survives as the informed capital $K$ gets close to $K_{3}$. The intuition is simple. If primary insurers supply reinsurance capacity, they reduce the amount they invest in their primary portfolio. Thus, the share of the surplus they can claim shrinks because they must earn the same return as reinsurers in equilibrium. If their share in the surplus shrinks too much, it is no longer compatible with their incentive compatibility constraint, which is binding for $K=K_{3}$.

At this stage, the reader may wonder why we have ruled out the possibility of reinsurers raising outside funds. This is because it is actually immaterial. All that matters in order to ease the financial constraint is a sufficient amount of informed financing (capital of primary insurers and reinsurers) being committed to a primary portfolio. Once this amount is provided, whether outside finance transits in reinsurers' balance sheets or not before ending in primary portfolios is irrelevant. ${ }^{5}$ This irrelevancy property, which simplifies the analysis, depends crucially upon perfect correlation. Relaxing this assumption would add another benefit from reinsurance to the one emphasized here. Indeed, diversification within reinsurance companies would mitigate their moral hazard problem, because reinsurance treaties could cross-pledge each other (see Tirole, 1996, for an exposition of this broad idea, closely related to the rationale for intermediation pioneered in Diamond, 1984). In this

\footnotetext{
${ }^{5}$ This point is similar to the "certification versus intermediation" point made in Holmstrom and Tirole (1997).
} 
case, it would be optimal to have reinsurers intermediating outside finance.

The next section studies the comparative statics of this equilibrium.

\section{Empirical Implications}

In this section, we determine the variations of the equilibrium cession rate $\alpha$ with respect to the parameters of the model in Proposition 3, then we derive empirical implications.

\section{Proposition 3}

The cession rate $\alpha$ increases with respect to $I, c_{R}$, and $\gamma$, and decreases with respect to $K$.

Proof. See the Appendix.

In order to gain some intuition and interpret these results, it is worth describing the effect of an increase in $\alpha$ in more detail. If the cession rate increases, primary insurers are more heavily reinsured in the sense that the reinsurance capacity $K_{R}$ provided to each portfolio increases. Thus, an increase in the cession rate reduces reinsurance profitability. Because primary insurance and reinsurance profitabilities cannot differ in equilibrium, the stake of primary insurers in the positive outcome is reduced. This makes more cash flows pledgeable to outside financiers, who at the same time have less capital to commit because $K_{R}$ has increased. As a result, an increase in the cession rate reduces the profitability of insurance and reinsurance while making outside finance more profitable. Eventually, an increase in the cession rate transfers value from insiders to outsiders to ease financial constraints. 
A first testable implication of these comparative static properties is therefore that reinsurance capacity and reinsurance profitability, both endogenous in our model, should be inversely related. Weiss and Chung (2004) find evidence in support of this point in the U.S. property and casualty reinsurance markets over 1991-1995.

The variation of $\alpha$ with respect to the exogenous parameters described in Proposition 3 may now be interpreted as follows.

Reinsurance and prudential regulation. The reason $\alpha$ increases with respect to $I$ is clear. If the exogenous capital requirement increases, it means that more outside finance is required. This increases the stake of outsiders in the cash flows, or reduces the stake of primary insurers and reinsurers. Because the stake of reinsurers must remain incentive-compatible, primary insurers have to reduce their stake. This makes reinsurance more profitable than primary insurance, hence more insurers give up their primary portfolio to exert reinsurance. As a result, this model delivers the well-known tradeoff between solvency and capacity of the primary insurance market faced by the regulator. Toughening capital requirements makes firms more solvent but reduces the number of primary portfolios underwritten $\left(1-\lambda=\frac{1}{1+\alpha}\right)$ and leads to more reinsurance. This relationship between reinsurance and regulation is well acknowledged by practitioners.

Reinsurance and moral hazard. If $c_{R}$ increases, the share of reinsurers in the cash flows has to increase, and in turn they have to supply more capacity; hence, $\alpha$ increases. The interpretation is that when the monitoring of primary insurers by reinsurers is more difficult, primary insurers cede more. We point out in the introduction that the reason risk managers are difficult to monitor 
in non-life business is because a long time elapses between claims occurence and settlement. The monitoring $\operatorname{cost} c_{R}$ should thus be all the larger because the primary business is a long-tailed one. Indeed, the true production costs of insurance are more noisily observed in this case. As a result, the prediction of the model is that primary insurers with long-tailed business should cede more, consistent with the findings of Garven and Lamm-Tennant (2003). Another reason the true costs of an insurance company are more difficult to assess is that they are volatile. Consistent with this, Hassan et al. (1990) find that firms with more volatile gross loss ratios demand more reinsurance.

Reinsurance and informed capital. The cession rate $\alpha$ decreases with $K$ because as $K$ increases, less outside finance is required and primary insurers, who provide a higher proportion of the funds, must have an increasing stake in the cash flows. In practice, firms with low inside capital are typically mutual firms, owned by their customers only by definition. We predict that, all else equal, these firms should be more reinsured than stock firms. Conversely, we predict that firms with a higher level of institutional ownership should be less reinsured, because institutional investors provide better informed capital on average. This is consistent with recent findings from Shortridge and Avila (2004).

Reinsurance and cost of capital. The cession rate $\alpha$ increases with respect to $\gamma$ because if outside investors require a higher return, then value must be transferred from insiders to outsiders. We have stressed that an increase in the cession rate is a mechanism to achieve this transfer in this model. This is broadly consistent with the soft reinsurance market observed during the late $1990 \mathrm{~s}$, during which time outside finance was cheap, and cession rates 
were low (see, e.g., The Worldwide Reinsurance Review, 1999). This is also consistent with the cross-sectional findings in Mayers and Smith (1990) that more widely held insurers demand less reinsurance: Stakes in such companies should be more liquid, which reduces the opportunity cost of outside capital.

\section{Concluding Remarks}

This paper offers a model of equilibrium in reinsurance and capital markets in which reinsurers arise endogenously. The pyramidal structure of the reinsurance market and the interaction between reinsurance and financing decisions are both addressed. The model, admittedly very stylized, is only a first step towards a theory of reinsurance, but the consistency of some of its predictions with empirical evidence is encouraging.

The main limitation of the paper is that it does not explain why monitors which, unlike reinsurers, do not commit capital — auditing firms and rating agencies - co-exist with reinsurers in the insurance industry. An interesting route for future research is to study the interplay of reinsurers with rating agencies and auditors, who do not intervene directly in firms' operations but issue public signals about firms' quality. Aghion et al. (2004) develop a model in which the issuance of a public signal by a "speculative" monitor increases the incentives of an "active" monitor involved in the management of a project. Their general approach suggests therefore that reinsurers and rating agencies provide complement rather than substitute monitoring services.

Another limitation of the paper is the minimalist (though in line with the view of practitioners) modelling of the interaction between the insurance company and the policyholders or their representatives, who can only impose 
a capital requirement. A richer modelling of this interaction is an interesting route for future research. However, this limitation has also an upside; indeed, it means that the point made here is fairly general and that "insurers" could be reinterpreted as "bankers," who contemplate lending money but are subject to a moral hazard problem. But then, why is it that the "rebankers" arising in the model seem absent from the real world? Note first that they are not totally absent. Some institutions such as MBIA for municipal bonds or Freddie Mac and Fannie Mae for housing loans strongly resemble reinsurers in the credit market, as they specialize in bearing the tails of credit risks, and this credit enhancement is a device to commit to monitor the originator. Note also that, interestingly, reinsurers are fairly active in credit markets, either by assuming a lot of credit reinsurance, ${ }^{6}$ or more recently by being big players in the credit derivatives market. However, such patterns are not as important in credit markets as they are in insurance markets, probably because they respond to a phenomenon - moral hazard due to the slow revelation of production costs - which is a first-order issue in property/casualty insurance but not in banking. Because they transform durations, distressed retail banks typically face liquidity problems much earlier than non-life insurance companies. Note that if moral hazard is not too important $\left(K \geq K_{2}\right)$, our model predicts that the agents should carry out both primary and secondary business, very much like banks who originate loans and intervene in the interbank market simultaneously.

\footnotetext{
${ }^{6}$ Credit insurance is indeed very reinsured.
} 


\section{Appendix}

\section{Proof of Proposition 1}

Assume that each insurer $i \in[0,1]$ is able to underwrite her insurance portfolio. Let $x_{i}$ denote the fraction of her capital $K$ she uses to supply reinsurance capacity to the other insurers. She and her reinsurers must have incentive compatible stakes $R_{I}^{i}$ and $R_{R}^{i}$ in case of a nonnegative outcome,

$$
R_{I}^{i} \geq \frac{b_{I}}{\Delta p}, R_{R}^{i} \geq \frac{c_{R}}{\Delta p}
$$

and the outside financiers must at least break even,

$$
p\left(R-R_{I}^{i}-R_{R}^{i}\right) \geq(1+\gamma)\left(I-\left(1-x_{i}\right) K-K_{R}^{i}\right),
$$

where $K_{R}^{i}$ is the capacity provided by $i^{\prime}$ s reinsurers. Thus, necessarily

$$
p\left(R-\frac{b_{I}}{\Delta p}-R \frac{c_{R}}{\Delta p}\right) \geq(1+\gamma)\left(I-\left(1-x_{i}\right) K-K_{R}^{i}\right)
$$

and the market for reinsurance capacity clears, so that

$$
\int_{0}^{1} x_{i} d i \times K=\int_{0}^{1} K_{R}^{i} d i .
$$

Thus, integrating the above inequality between 0 and 1 , one finds that a necessary condition for each insurer underwriting her primary portfolio is

$$
p\left(R-\frac{b_{I}}{\Delta p}-\frac{c_{R}}{\Delta p}\right) \geq(1+\gamma)(I-K) .
$$




\section{Proof of Proposition 3}

Recall the definitions of $\alpha, \rho_{I}$, and $\rho_{R}$ :

$$
\begin{aligned}
\alpha & =\frac{1}{2}\left(\sqrt{\rho_{I}^{2}+4 \rho_{R}}-\rho_{I}\right) \\
\rho_{I} & =1+\frac{p\left(R-\frac{c_{R}}{\Delta p}\right)-(1+\gamma) I}{(1+\gamma) K} \\
\rho_{R} & =\frac{(p-\Delta p)}{(1+\gamma) K} \frac{c_{R}}{\Delta p} .
\end{aligned}
$$

Hence,

$$
\begin{aligned}
& \frac{\partial \alpha}{\partial \rho_{I}}=-\frac{\alpha}{2 \alpha+\rho_{I}}<0 \\
& \frac{\partial \alpha}{\partial \rho_{R}}=\frac{1}{2 \alpha+\rho_{I}}>0 .
\end{aligned}
$$

It follows that

1. $\alpha$ increases w.r.t. $I$ because $\rho_{I}$ decreases w.r.t. $I$.

2. $\alpha$ increases w.r.t. $c_{R}$ because $\rho_{I}$ and $\rho_{R}$ decrease and increase, respectively, w.r.t. $c_{R}$.

3.

$$
\frac{\partial \alpha}{\partial \gamma}=\frac{\partial \alpha}{\partial \rho_{I}} \frac{\partial \rho_{I}}{\partial \gamma}+\frac{\partial \alpha}{\partial \rho_{R}} \frac{\partial \rho_{R}}{\partial \gamma}
$$

Moreover,

$$
\begin{aligned}
\frac{\partial \rho_{I}}{\partial \gamma} & =-\frac{I-K}{(1+\gamma) K}-\frac{\rho_{I}}{1+\gamma} \\
\frac{\partial \rho_{R}}{\partial \gamma} & =-\frac{\rho_{R}}{1+\gamma} .
\end{aligned}
$$

Thus,

$$
\frac{\partial \alpha}{\partial \gamma}=\frac{1}{\left(2 \alpha+\rho_{I}\right)(1+\gamma)}\left(\alpha\left(\rho_{I}+\frac{I}{K}-1\right)-\rho_{R}\right) .
$$


Now remember that, by definition,

$$
\rho_{I} \alpha-\rho_{R}=-\alpha^{2}
$$

Hence,

$$
\frac{\partial \alpha}{\partial \gamma}=\frac{\alpha}{\left(2 \alpha+\rho_{I}\right)(1+\gamma)} \times\left(\frac{I}{K}-1-\alpha\right)>0
$$

because the term between parentheses is nonnegative since $\alpha<\frac{I}{K}-1$ means that $K_{R}+K<I$, which is the case in equilibrium.

We have

$$
\frac{\partial \alpha}{\partial K}=\frac{\partial \alpha}{\partial \rho_{I}} \frac{\partial \rho_{I}}{\partial K}+\frac{\partial \alpha}{\partial \rho_{R}} \frac{\partial \rho_{R}}{\partial K}
$$

and

$$
\begin{aligned}
\frac{\partial \rho_{I}}{\partial K} & =\frac{1-\rho_{I}}{K} \\
\frac{\partial \rho_{R}}{\partial K} & =-\frac{\rho_{R}}{K} .
\end{aligned}
$$

Thus,

$$
\frac{\partial \alpha}{\partial K}=\frac{1}{\left(2 \alpha+\rho_{I}\right) K}\left(\alpha\left(\rho_{I}-1\right)-\rho_{R}\right)=\frac{-\alpha^{2}-\alpha}{\left(2 \alpha+\rho_{I}\right) K}<0
$$




\section{References}

[1] Aghion P., Bolton P., and Tirole J. (2004) "Exit Options in Corporate Finance: Liquidity versus Incentives," Review of Finance, 8 (3), 327353.

[2] Berger A., Miller N., Petersen M., Rajan R., and Stein J. (2001) "Does Function Follow Organizational Form? Evidence From the Lending Practices of Large and Small Banks", mimeo University of Chicago.

[3] Borch K. (1962) "Equilibrium in a Reinsurance Market", Econometrica, 30, 424-444.

[4] Dewatripont M. and Tirole J. (1994) "The Prudential Regulation of Banks", MIT Press.

[5] Diamond D. (1984) "Financial Intermediation and Delegated Monitoring", The Review of Economic Studies, 51 (3), 393-414.

[6] Doherty N. A. and Smetters K. (2002) "Moral Hazard in Reinsurance Markets", working paper

[7] Doherty N. A. and Tinic S.M. (1981) "Reinsurance under Conditions of Capital Market Equilibrium: A Note", The Journal of Finance, 36 (4), 949-953.

[8] Garven J. R. and Lamm-Tennant J. (2003) "The Demand for Reinsurance: Theory and Empirical Tests", Insurance and Risk Management, 71 (2), 217-237. 
[9] Hassan M., Hoerger T. J., and Sloan F. (1990), "Loss Volatility, Bankruptcy, and the Demand for Reinsurance", Journal of Risk and Uncertainty, 3 (3), 221-245.

[10] Holmström B. and Tirole J. (1997) "Financial Intermediation, Loanable Funds and The Real Sector", Quarterly Journal of Economics, 112, 663-692.

[11] Innes R. D. (1990) "Limited liability and incentive contracting with exante action choices", Journal of Economic Theory, 52 (1), 45-67.

[12] Mayers D. and Smith Jr C. W. (1990) "On the Corporate Demand for Insurance: Evidence from the Reinsurance Market", Journal of Business, 63 (1), 19-40.

[13] Swiss Re (1998) "The global reinsurance market in the midst of consolidation", Sigma $\mathbf{n}^{\circ} \mathbf{9} / \mathbf{1 9 9 8}$.

[14] The Worldwide Reinsurance Review. November 1999.

[15] Tirole J. (1996) "Lecture Notes on Corporate Finance", mimeo University of Toulouse.

[16] Shortridge R. T. and Avila S. M. (2004) "The Impact of Institutional Ownership on the Reinsurance Decision", Risk Management ES Insurance Review, 7 (2), 93-106.

[17] Weiss M. A. and Chung J. (2004), "U.S. Reinsurance Prices, Financial Quality, and Global Capacity", Journal of Risk $\mathcal{G}$ Insurance, 71 (3), 437-467. 